\title{
Erratum
}

\section{Erratum: Gurtubay-Antolin et al., Neural Evidence of Hierarchical Cognitive Control during Haptic Processing: An fMRI Study}

In the article "Neural Evidences of Hierarchical Cognitive Control during Haptic Processing: An fMRI Study," by Ane Gurtubay-Antolin, Patricia León-Cabrera, and Antoni Rodríguez-Fornells, which published online on November 15, 2018, the reference citations on pages 8-9 appeared incorrectly. Additionally, the title should read "Neural Evidence of Hierarchical Cognitive Control during Haptic Processing: An fMRI Study." These errors do not affect the conclusions of the paper. The article has been updated online.

https://doi.org/10.1523/ENEURO.0504-18.2018 